\title{
Educational Futures and Postdigital Science
}

\section{David W. Kupferman ${ }^{1}$}

Accepted: 26 May 2021/ Published online: 10 June 2021

(c) The Author(s), under exclusive licence to Springer Nature Switzerland AG 2021

Keywords Futures studies · Educational futures - Science fiction · Cyberpunk ·

Postdigital science $\cdot$ Postdigital humans $\cdot$ Postdigital capitalism

\section{Anticipate, Not Predict}

\author{
I've got a secret \\ I've been hiding \\ Under my skin. \\ My heart is human \\ My blood is boiling \\ My brain IBM. \\ Styx, 'Mr. Roboto'1
}

In the year 2021, a global pandemic rages. Big Pharma holds the cure. Public protests roil the streets of major metropolises. Social media is used to expose corporate secrets. Organized crime syndicates use computer viruses to protect entrenched interests. The world is split in two, one real and one virtual, both of which run on data and are powered by the Internet. Random video images become non-fungible tokens, valuable commodities for the blockchain data they unlock.

This summary seems to capture some of the highlights of our own lived 2021. I also like to think that this was the pitch used to sell the movie Johnny Mnemonic (Longo 1995), written by William Gibson and based on his short story of the same name (Gibson 1986). Starring Keanu Reeves as the title character, the story follows Johnny, whose brain has been augmented by a wet-wired implant that allows him to upload large amounts of data. Working as a data courier, Johnny smuggles data from a pair of scientists in Beijing who need to get the information to Newark, New Jersey. The world is suffering from a pandemic known as Neural Attenuation Syndrome

\footnotetext{
1 See https://youtu.be/uc6f_2nPSX8. Accessed 26 May 2021.

David W. Kupferman

david.kupferman@mnstate.edu

1 Minnesota State University Moorhead, Moorhead, MN, USA 
(NAS), brought on by the dependency people have on technology. The data Johnny is carrying contain the cure to NAS. During the upload, the Yakuza, working on behalf of Pharmakom, the largest pharmaceutical corporation in the world, kill the scientists and try to hunt down Johnny. While in Newark, Johnny joins up with a group of hackers who live off the grid, called LoTeks, and who, with the aid of a post-cetacean dolphin named Jones, are able to download the data, including the cure for NAS, before Johnny suffers an overload and permanent brain damage.

What makes Johnny Mnemonic compelling for us is that it serves as a text for futures studies, and specifically for educational futures. In sum, futures studies are a way to anticipate, rather than predict, different futures: the probable, the possible, and the preferable. Given that we are now all too familiar with the year 2021, the movie offers a way to compare what 2021 could have been from the perspective of the time it was made (in the mid-1990s), and to marvel at how presciently it got things right for our present, as well as our futures.

The movie also provides an example of how science fiction-in this case cyberpunk-imagines for us any number of futures. While much of futures studies takes place in the world of policy and proscription, turning our focus to the popular social imaginary, in the form of short stories, movies, and other media, lets us create tangible dispatches from the future (Kupferman 2020a). And when we live to see that time, as we now get to see and experience 2021, we can appreciate the ways in which these dispatches get things very wrong and very right-which in turn help us to anticipate further probable, possible, and preferable futures.

Wendell Bell (1997/2003), an early voice in the theorizing of the field, suggests that futures studies is both an art and a science. Art and science, he argues, have long influenced each other, even as science seeks the truth while art is under no obligation to do so. An argument can — and should-be made in defense of art in this regard, as art often uncovers truths that science does not, or cannot, explain. And Bell also points out that 'the future is not factual' (1997/2003: 173), in that it cannot be replicated or validated. The important thing to keep in mind, it seems to me, is that there is no one way to do futures studies. I find that the more interesting approach to futures studies is to remember that it is an art. And the art upon which I prefer to draw is one we are all familiar with: science fiction. There is good theory in science fiction, and we would do well to begin using it (Kupferman 2020b).

\section{Science Is Not Acting Like Science These Days}

If there is one field of inquiry that would benefit from and could easily call on science fiction, it is postdigital science. While the term 'postdigital' is contested, and perhaps not even a helpful term, it describes the increasingly blurry lines of technology, media, and science as we move farther and farther away from the digital revolution of the second half of the twentieth century (Jandrić et al. 2018; Knox 2019). 
The ubiquity of the Internet in everyday life — down to our biometric data-suggests that we are in an age far beyond that of the early stages of the World Wide Web. Instead, we now live in an Internet of Everything 'where physical and digital worlds are blended into a single space' (Greengard 2015: 18).

Perhaps a better way to understand postdigital science is to consider it more as an art (in this case science fiction), because even science is not acting like science these days. The discovery that muons fail to follow the laws of quantum physics suggests that science needs science fiction far more than science fiction needs science (Cho 2021). And analyses of educational futures-what will pedagogy, posthuman and machine learning, and capital networks influencing educational processes and systems look like in various future scenarios-stand to benefit from more creativity and imagination. We have any number of examples to explore, from novel approaches to mapping out educational futures (such as a wonderful piece by Costello et al. (2020)) to illustrations of our contemporary condition, such as that provided by Johnny Mnemonic. It is to the latter that we now turn, so that we can begin to lay the foundation for more of the former in educational futures.

By now, some of the conceits of Johnny Mnemonic, while original at the time, have become fairly commonplace. This is the first film, for example, wherein Keanu Reeves uses a cortical knowledge upload (CKU) device, but certainly the version in The Matrix (Wachowski Brothers 1999), wherein as Neo he literally plugs a computer into the back of his head to learn kung fu, is the one most people have in mind. There is also the idea of the plasticity of the brain: here, Johnny's brain is able to adapt to the data overload he endures, surviving the ordeal of exceeding the storage capacity in his head. Both of these cases suggest some sort of engagement with questions of postdigital pedagogy and learning, as well as issues of the ethics of posthumanism.

Perhaps less obvious in terms of the former, yet vital to considerations of educational futures, is what is lost in the process of learning through CKUs. While on the run, Johnny partially explains what it means to be a data courier to Jane, who has just saved him from the Yakuza:

Johnny: 'Implant, wet-wired. I had to dump a chunk of long-term memory.'

Jane: 'You had to dump a chunk of what?'

Johnny: 'My childhood.'

Later, Johnny remarks, 'I needed the space for the job'. In the original short story, Johnny tells the reader, 'I had no idea at all of what was really happening, or of what was supposed to happen. And that was the nature of my game, because I'd spent most of my life as a blind receptacle to be filled with other people's knowledge and then drained' (Gibson 1986: 23). It is worth wondering, in a possible future, what it would take to learn in this way, and what the cost would be. In the case of Johnny, there is a loss of innocence, suggesting that childhood is both expendable and not actually meaningful in terms of the ability of the brain to adapt to technological advances (Simpson and Gibbons 2019). It is also worth asking what we might lose of ourselves in the process of building a postdigital educational future. 


\section{Postdigital Humans}

To the latter issue, that of posthumanism, there is a brief moment when, as Johnny is being scanned upon entering Newark, we see in x-ray his wet-wired implant. The text on the bottom of the screen reads: 'DYSLEXIA PROSTHESIS IMPLANT, GOVERNMENT APPROVED'. Was the implant originally designed to remedy a learning disability, or is that a false flag for the authorities, covering up the fact that Johnny is a data smuggler? The film does not answer this question, but either way it does imply a level of posthumanism in 2021.

Much has been written about posthumanism and adjacent transhumanism, often in terms of the Anthropocene or its end, and so it does not need to be belabored here. What is compelling about this detail, however, is the question of what it means to 'correct' disability, and what the implications are for, say, special education. In her short story 'Girl in Wave: Wave in Girl', Kathleen Ann Goonan (2014) posits a posthuman future in which medical procedures to eliminate learning difficulties give way to biological enhancements such as children with wings (or, in the case of Johnny, the ability to carry large packets of data in one's brain). Is this a preferable future? And if so, what are the ethical repercussions of 'fixing' certain learning needs? Does special education even exist in a world of postdigital science? And if so, what does it look like?

A third consideration for educational futures and postdigital science from the movie, and perhaps one that deserves more investigation for critical education futurists, involves a minor character who is not even human anymore. The image of a woman's face appears periodically throughout the film, providing clues and filling in context for both Johnny and Takahashi, the CEO of Pharmakom whose daughter had died of NAS. This AI image turns out to be Anna Kalmann, the founding CEO of the same multinational pharmaceutical corporation. When Takahashi asks his secretary who the AI is, his secretary tells him that she 'was imprinted to Pharmakom's neural-net installation in Zurich prior to onset of morbidity... Her neural-net persona has Swiss citizenship under the artificial intelligence laws of 2006. She advises the current board from this state of being' (Longo 1995). Here we have a future in which the mind of a biologically deceased person has been uploaded to the Internet - and that mind continues to function as it did biologically.

The notion of one's mind outliving one's body, and continuing to exist virtually, is taken seriously not only in popular media, but also in corners of neuroscience. The Blue Brain Project in Switzerland is currently using supercomputers to digitally recreate the brain of a mouse (École Polytechnique Fédérale de Lausanne 2021). In so doing, it is pioneering fields such as neurobotics and neuromorphic computing with the aim of reconstructing the human brain. Much of what constrains their work is technological — the computing power required to map a human brain likely exceeds what is currently available. But if Moore's law should apply to neuro-mapping, it suggests a possible future wherein one's brain gets uploaded to the cloud.

So will we need to maintain the body if the brain can move into a virtual realm, and not only survive but continue to thrive there? If so, what is biology to artificial intelligence? Is biology necessary for postdigital science? And what happens to 
ideas and processes like education? Do we still learn as minds in the cloud? To add yet another wrinkle, Ernest Cline (2020) takes this concept a step further in Ready Player Two, in which the protagonist, Wade Watts, discovers that he can make a copy of anyone to live in the OASIS virtual universe, seemingly forever. Wade makes copies of himself and his friends (as well as the rest of humanity) and uploads them to the OASIS. But something new happens, in which you and your avatar then split off and begin to lead separate lives. So the living, biological Wade will eventually die (as will his biological consciousness), while the avatar Wade will live on in eternity.

For our purposes, it seems important to ask what you are if your brain is uploaded into the cloud, and then has its own 'life' even though it shares your memories? Are you immortal? Which version is 'you'? What is mortality to AI? (see Savin-Baden (2021), and Savin-Baden and Mason-Robbie (2020), for some possible answers and even more questions.) And if any of this is even remotely possible, we must ask the ethical question of whether or not this is preferable in terms of educational futures. How much of education needs to be directed by people, and how much do we cede to AI-especially if that AI was originally biological?

\section{Postdigital Capitalism}

Perhaps the one plot point in Johnny Mnemonic that could only be understood in 2021 is the code that unlocks the data in his head, and the way that value is derived from random images. Early on when Johnny is preparing for the data upload that drives the movie, he explains to his clients what they need to do as the process nears completion:

When the counter approaches zero, click on three frames off the TV. Any three. They'll meld with the data and I won't know what they are. That's the download code. You get a hard copy. You fax one copy to your connection on the other side. When I get there, we feed in the code and download. (Longo 1995)

These three random images - a cartoon superhero, security camera footage of a crowd, and a face evoking a ghost in the machine-are partially destroyed before they can be transmitted when the Yakuza show up, and Johnny escapes the encounter with half of the frames.

These non-fungible tokens (NFTs) are important for a number of reasons. The first is that, much like NFTs in our 2021, these random images imbue certain data with value. In the case of Johnny Mnemonic, the value is in the data he has uploaded to his wet-wired implant. Without these NFTs, the data are irretrievable. In our version of reality, NFTs have, in 2021, somehow become a new form of currency, the data of random images that have generated surprising amounts of wealth and value in a short period of time. Essentially 'unique' images on a blockchain (although since the images are data they are therefore theoretically available to everyone on 
the Internet, albeit as 'copies'), NFTs are now a source of raising actual money through online auctions.

In April 2021 the Golden State Warriors basketball team became the first professional sports organization to release their own set of NFTs. Others-some artists, some people who gained fame through Internet memes-are selling images in the millions of dollars to buyers who then have the privilege of 'owning' the blockchain. (To be clear, no one quite seems to understand NFTs, beyond the idea that they constitute manufactured scarcity for the shareholder class.) The conceit at work here is that value exists in owning an 'original'. But what constitutes the origin of data? And, evoking Baudrillard, what is original anymore in a universe of copies?

Beyond the question of what NFTs are is the question of how they work, and what they mean for a postdigital capitalism. For over a decade, cryptocurrency has become increasingly legitimate capital for a postdigital age. Bitcoin, Dogecoin, and Ethereum (to name but a few) are now leveraged as currency in the open market, using blockchain to purchase tangible items in the real world. NFTs seem poised to push this form of virtual value over the edge.

NFTs, which are not material 'things', can conceivably be bought at auction by currency that is itself not material. It is a free market that is free of reality, where value is capricious by design, making a parody of the social cost of production in Marx's labor theory of value. Indeed, the entire notion of NFTs suggests that there is no need anymore for the use value of a commodity, since the image has already been downloaded and shared billions of times. Instead, like the data in Johnny's head which can only be unlocked by a code comprised of three random images, we have entered a form of capitalism where exchange value is traded for exchange value. This is far from a post-capitalist world. This is the next iteration of capitalism, a flexing of its muscles that even Marx could not predict (see Ford and Jandrić (2021), for more on Marxism and the virtualization of capital).

So what does this postdigital capitalism provide for us in terms of understanding educational futures? Scott Galloway (in Reed 2021) offers the following scenario: Stanford, which, due to its endowment, now operates effectively like a hedge fund that happens to also run a university, decides it wants to raise $\$ 100$ billion by issuing its own Stanford crypto-coins. Each coin goes for $\$ 1$ million dollars, and those who buy them get a set of perks based on contracts written on top of each coin: tuition to Stanford, access to sports events, university parties, and perhaps even to allocate admission for students from communities of color and low-income neighborhoods. This situation, which is certainly possible (if not probable), begs a few questions. What happens to the lie of the meritocracy? How does Stanford fulfill its mission of educating the brightest students from across the socio-economic spectrum? How long does the system hold together when the shareholder class-in this case, the wealthy who own a Stanford coin-literally gets to play god with the futures of students of color and students from poor areas, deciding who gets in and who doesn't?

The future of college admission and tuition here exists squarely in a space of postdigital capitalism. And for universities that do not have the endowment or financial pull of Stanford, such as state schools, there is now also the option of raising funds by auctioning off NFTs. It seems that anyone can sell an NFT. The woman behind the Disaster Girl meme from 2005 raised half a million dollars auctioning 
the NFT of the image of her smirking as a house burns in the background. Certainly mid- and lower-tier colleges and universities will begin to sell NFTs of, say, graduation ceremonies, homecoming parties, and perhaps even campus tours. So is this the true future of the postdigital university, one in which tuition is paid for-and admission available — now only in blockchain? And if so, what does this portend for higher education in an age of already unsustainable economic inequality?

\section{Postdigital Educational Futures}

At the end of Johnny Mnemonic, the data from Pharmakom is downloaded from Johnny's head, providing a cure to Nerve Attenuation Syndrome. But there the story ends. We do not get to see what happens next, and how (or if) society resets itself. Left unanswered is the question of what cyberpunk becomes once there is an antidote for the ravages of technology. There is no resolution to issues of technological enhancement of humans as data couriers, no consideration of the ethics of postdigital technology's role in the daily lives of average people, no exploration of the use of NFTs in the evolution of a postdigital capitalism. Matters of pedagogy and the movement of learning — and living — to virtual spaces are left unsettled.

As the vaccines for Covid-19 are rolled out in the first half of our 2021, we also have yet to see what happens next. Will we learn anything from the pandemic? With the push to return to 'normal' — especially in a return to schools and schooling-will anything have changed? After a year on Planet Zoom, will we reconsider our trajectory towards a postdigital future? Will we, finally, start to consider the multiple educational futures that should (and those that should not) await us? The fear, I think, is that, once we pull off our masks and 'resume' our lives, we will look at 2020-2021 as a blip, an interruption, rather than as an opportunity to reset. If we do that, we will miss the chance to rewire different futures. We need more dispatches from the future (Costello et al. 2020; Kupferman 2020a). Postdigital science is a wide-open field. How it intersects with educational futures should be wide open as well (see Knox (2019), for an opening salvo in this regard). We need to dream up what comes next and let our imaginations run wild, so that we begin to anticipate the various potentials of postdigital educational futures, rather than backing into them and hoping that we get it right.

\section{References}

Bell, W. (1997/2003). Foundations of Futures Studies I: History, purposes, knowledge. New Brunswick, NJ: Transaction Publishers.

Cho, A. (2021). Particle mystery deepens, as physicists confirm that the muon is more magnetic than predicted. Science, 7 April. https://www.sciencemag.org/news/2021/04/particle-mystery-deepensphysicists-confirm-muon-more-magnetic-predicted. Accessed 20 May 2021.

Cline, E. (2020). Ready player two. New York: Ballantine Books.

Costello, E., Brown, M., Donlon, E., \& Girme, P. (2020). 'The pandemic will not be on Zoom': A retrospective from the year 2050. Postdigital Science and Education, 2(3), 619-627. https://doi.org/10. 1007/s42438-020-00150-3. 
École Polytechnique Fédérale de Lausanne. (2021). Blue brain project. https://www.epfl.ch/research/ domains/bluebrain/. Accessed 20 May 2021.

Ford, D. R., \& Jandrić, P. (2021). Postdigital Marxism and education. Educational Philosophy and Theory. https://doi.org/10.1080/00131857.2021.1930530.

Gibson, W. (1986). Burning Chrome. London: Orion.

Goonan, K. A. (2014). Girl in wave: Wave in girl. In E. Finn \& K. Cramer (Eds.), Hieroglyph: Stories and visions for a better future (pp. 38-73). New York: William Morrow.

Greengard, S. (2015). The internet of things. Cambridge, MA: MIT Press.

Jandrić, P., Knox, J., Besley, T., Ryberg, T., Suoranta, J., \& Hayes, S. (2018). Postdigital Science and Education. Educational Philosophy and Theory, 50(10), 893-899. https://doi.org/10.1080/00131857. 2018.1454000 .

Knox, J. (2019). What does the 'postdigital' mean for education? Three critical perspectives on the digital, with implications for educational research and practice. Postdigital Science and Education, 1(2), 357-370. https://doi.org/10.1007/s42438-019-00045-y.

Kupferman, D. W. (2020a). I, robot teacher. Educational Philosophy and Theory. https://doi.org/10.1080/ 00131857.2020.1793534.

Kupferman, D. W. (2020b). (Nothing but) futures. ACCESS: Contemporary Issues in Education, 40(1), 5-8. https://doi.org/10.46786/ac20.2409.

Longo, R. (1995). Johnny Mnemonic [Motion picture]. Culver City, CA: TriStar Pictures.

Reed, J. (2021). BidenBucks is Beeple is Bitcoin. New York Magazine, 12 April. https://nymag.com/ intelligencer/2021/04/unified-monetary-theory-beeple-biden.html. Accessed 26 May 2021.

Savin-Baden, M. (Ed.). (2021). Postdigital humans: Transitions, transformations, and transcendence. Cham: Springer. https://doi.org/10.1080/00131857.2021.1930530.

Savin-Baden, M., \& Mason-Robbie, V. (Eds.). (2020). Digital afterlife: Death matters in a digital age. Boca Raton, FL: CRC Press.

Simpson, P. W., \& Gibbons, A. (2019). Filling the mind: Cortical knowledge uploads, didactic downloads, and the problem of learning in the future. In D. W. Kupferman \& A. Gibbons (Eds.), Childhood, science fiction, pedagogy: Children ex machina (pp. 155-170). Singapore: Springer. https:// doi.org/10.1007/978-981-13-6210-1_9.

Wachowski Brothers. (1999). The Matrix [Motion picture]. Los Angeles: Warner Bros. 